\title{
Adopting Guidelines into Clinical Practice: Implementation of Trastuzumab in the Adjuvant Treatment of Breast Cancer in Lower Saxony, Germany, in 2007
}

\author{
Clemens Liebrich $^{\mathrm{a}}$ Günter Unger ${ }^{\mathrm{b}}$ Birgit Dlugosch ${ }^{\mathrm{b}}$ Stefan Hofmann ${ }^{\mathrm{b}} \quad$ Karl U. Petry

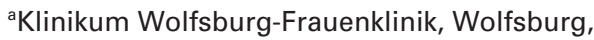 \\ ${ }^{\mathrm{b} K a s s e n a ̈ r z t l i c h e ~ V e r e i n i g u n g ~ N i e d e r s a c h s e n, ~ H a n n o v e r, ~ G e r m a n y ~}$
}

\section{Keywords}

Adjuvant treatment - Breast cancer - Quality control . Trastuzumab · ONkeyLINE system

\section{Summary}

Background: Few studies have assessed the quality of medical care in breast cancer patients outside clinical studies and certified centres in German-speaking countries. We used ONkeyLINE, a voluntary tumour registry, to evaluate the rate of adoption into clinical practice of guidelines on the adjuvant use of trastuzumab and to estimate the reliability of ONkeyLINE in assessing quality of care. Material and Methods: Data from ONkeyLINE were analysed to answer questions on the quality of breast cancer care in daily practice in 2007 . The influence of age and area (rural/urban) on treatment patterns was also evaluated. Results: Data from approximately $85 \%$ of patients diagnosed with breast cancer in Lower Saxony in 2007 were documented in ONkeyLINE. Within 1 year, more than $77 \%$ of patients received adjuvant trastuzumab according to the updated guidelines. Variations in chemotherapy and trastuzumab according to age were evident, in part but not fully attributable to comorbidities in the elderly. Access to trastuzumab therapy in rural areas was as high as in urban areas. Conclusions: Adoption of national guidelines into clinical practice was observed at a reasonable but still unsatisfactory rate in Lower Saxony. Although voluntary, ONkeyLINE covered most breast cancer cases and proved to be a reliable tool for assessing quality of care.

\author{
Schlüsselwörter \\ Adjuvante Therapie · Mammakarzinom · Qualitäts- \\ kontrolle · Trastuzumab · ONkeyLINE-System
}

\section{Zusammenfassung}

Hintergrund: Systematische Untersuchungen zur Qualität der Routinebehandlung von Brustkrebs außerhalb von Studien und zertifizierten Zentren fehlen in den deutschsprachigen Ländern weitgehend. Mit der vorliegenden Analyse von ONkeyLINE, einem freiwilligen, Internetbasierten, niedersächsischen Tumorregister sollte untersucht werden, wie rasch nationale Leitlinien zum adjuvanten Einsatz von Trastuzumab in die klinische Routine umgesetzt wurden und wie die Zuverlässigkeit von ONkeyLINE als Mittel zur Qualitätskontrolle einzuschätzen ist. Material und Methoden: Die Qualität der Diagnostik und Therapie von Brustkrebs im klinischen Alltag des Jahres 2007 wurde anhand von ONkeyLINE-Daten für Niedersachsen unter Berücksichtigung eines möglichen Einflusses des Lebensalters und der Region (ländlich/städtisch) untersucht. Ergebnisse: Ungefähr 85\% aller 2007 in Niedersachsen diagnostizierten Brustkrebsfälle wurden in ONkeyLINE erfasst. Ein Jahr nach Veröffentlichung der Leitlinien erhielten mehr als $77 \%$ der Patientinnen eine adjuvante Trastuzumab-Therapie. Es ergaben sich altersabhängig deutliche Unterschiede beim Einsatz von Zytostatika und Trastuzumab, die nicht vollständig durch eine erhöhte Komorbidität der älteren Patientinnen erklärt werden konnten. Beim Einsatz von Trastuzumab bestanden dagegen zwischen ländlichen und urbanen Regionen keine Unterschiede. Schlussfolgerungen: Die Umsetzung von Leitlinien war akzeptabel, aber nicht optimal. Obwohl ONkeyLINE ein freiwilliges Tumorregister ist, wurde die große Mehrheit der Brustkrebsfälle in Niedersachsen vollständig erfasst, eine zuverlässige Qualitätskontrolle scheint daher mit diesem Tumorregister möglich.

\section{KARGER \\ Fax +497614520714 \\ Information@Karger.de}

www.karger.com (c) 2011 S. Karger GmbH, Freiburg

$1661-3791 / 11 / 0061-0043 \$ 38.00 / 0$

Accessible online at:

www.karger.com/brc
Prof. Dr. med. Karl Ulrich Petry

Dr. med Clemens Liebrich

Klinikum Wolfsburg. Frauenklinik

Sauerbruchstr. 7, 38440 Wolfsburg, Germany

Tel. +49 536180 1-270, Fax -613

gyn@klinikum.wolfsburg.de 


\section{Introduction}

Breast cancer is the most common cancer among women and the most common cause of cancer death in women aged between 30 and 60 years in the Western hemisphere. In Lower Saxony, Germany, the annual incidence of breast cancer is approximately 6,300 (6,250 women and 50 men) [1]. During the last decade, breast cancer mortality has declined in several countries. However, little is known about the relative contribution of improved screening and/or new therapies, or the extent to which evidence-based recommendations are adopted into clinical practice. In the USA, the surveillance, epidemiology, and end results (SEER) database provides detailed information on presentation and survival in patients from their primary presentation. In Europe, ONCOPOOL (Pooling of European Data to Harmonise Translation Research in Breast Cancer) provides retrospectively recorded data from almost 17,000 women treated in 12 European breast cancer units in 10 countries [2]. However, a weakness of ONCOPOOL is the exclusion of women aged $>70$ years. It is estimated that $45 \%$ of new cases of breast cancer in Germany will be in women aged $\geq 65$ years, including more than 3,000 cases in women aged $\geq 85$ years [3], yet there are few data on the elderly. There are several reports in the literature indicating that elderly patients with breast cancer are undertreated. Specifically in Germany, the OVIS study in Schleswig-Holstein assessed implementation of S3 breast cancer guidelines and the influence of age on breast cancer care in women up to 85 years of age. However, the study relied on patients completing a paper-based survey, which limits the reliability of data describing medical details [4]. Furthermore, the data are relatively old, collected for 2 years up to February 2005, and therefore provide no information on the uptake of newer guidelines in breast cancer, such as adjuvant trastuzumab therapy.

ONkeyLINE is a web-based tool of the 'Association of Preferred Providers of Lower Saxony' (Kassenärztliche Vereinigung Niedersachsen, KVN), in which patients' diagnostic and treatment details are documented for a range of cancer types. Information can be entered only by registered medical personnel and institutions using a secure passwordcontrolled registration and PIN-generated security token which changes every minute $[5,6]$. Data from more than 360,000 patients with various tumour types have been recorded in ONkeyLINE, including details on diagnostic findings, therapy, and long-term follow-up of each patient.

In Germany, most patients with breast cancer undergo primary surgical treatment in gynaecological departments. There are broad recommendations from the Health Ministry and cancer societies to concentrate primary treatment in cancer centres, but to date other institutions have not been excluded from breast cancer treatment.

Most hospital-based cancer centres and private practices specialising in oncology are linked to ONkeyLINE. The majority of institutions without cancer centres also transmit their data. For general practitioners and other physicians who are involved in the follow-up of cancer patients, reimbursement depends on the documentation of follow-up data in $\mathrm{ON}$ keyLINE. Complete records for approximately $85 \%$ of all breast cancer patients in Lower Saxony are available in the database, enabling robust assessment of the quality of routine medical care for women with breast cancer in this region. We analysed the data to try to determine the extent to which guidelines are adopted in Germany, particularly in older patients, and to understand whether the standards required in certified breast cancer clinics are met more generally in routine clinical practice.

\section{Patients and Methods}

\section{Data Selection}

All patients first diagnosed with breast cancer in 2007, who were registered in ONkeyLINE up to 31 May 2009, were included in the current analysis. We planned to answer the following questions on diagnosis and treatment patterns using data captured in ONkeyLINE:

\section{Diagnosis}

1. How often is hormone receptor status recorded in patients with invasive breast cancer?

2. Is HER 2 status recorded in all patients with invasive breast cancer and are there differences in HER2 status distribution between the adjuvant and metastatic settings?

3. What proportion of patients with invasive breast cancer have HER2positive tumours?

Table 1. Age at first diagnosis and type of tumour

\begin{tabular}{lc}
\hline Characteristics & Patients, $\mathrm{n}(\%)$ \\
\hline Gender & \\
Female & $5,370(99.5)$ \\
Male & $27(0.5)$ \\
Age, years & $1(0.02)$ \\
$<20$ & $18(0.3)$ \\
$20-29$ & $182(3.4)$ \\
$30-39$ & $774(14.3)$ \\
$40-49$ & $1,279(23.7)$ \\
$50-59$ & $1,873(34.7)$ \\
$60-69$ & $897(16.6)$ \\
$70-79$ & $356(6.6)$ \\
80-89 & $17(0.3)$ \\
90-99 & \\
Histopathology & $485(9.0)$ \\
In situ & $467(8.7)$ \\
DCIS & $12(0.2)$ \\
LCIS & $6(0.1)$ \\
Other non-invasive & $4,912(91.0)$ \\
Invasive & $3,949(73.2)$ \\
Ductal carcinoma & $598(11.1)$ \\
Lobular carcinoma & $106(2.0)$ \\
Ductal and lobular & $83(1.5)$ \\
Mucinous adenocarcinoma & $47(0.9)$ \\
Tubular carcinoma & $34(0.6)$ \\
Medullar carcinoma & $85(1.6)$ \\
Other & \\
Tumour stage & $3,528(65.4)$ \\
Local (any T, N0, M0) & $1,552(28.8)$ \\
Regional (any T, N+, M0) & $217(4.0)$ \\
Distant (any T, any N, M1) & $90(1.7)$ \\
Data missing & \\
\hline DCIS = Ductal carcinoma in situ; LCIS = lobular carcinoma in situ. \\
\multicolumn{2}{c}{. } \\
\hline
\end{tabular}


Treatment

1. How many patients with invasive breast cancer and positive hormone receptor status receive endocrine therapy?

2. How many patients receive chemotherapy in the adjuvant versus the palliative/metastatic setting?

3. How many patients receiving chemotherapy are aged $\geq 70$ years?

4. Are patients with invasive breast cancer and negative or unknown HER2 status treated with trastuzumab?

5. How many patients treated with trastuzumab are aged $\geq 60$ years?

6. Are there differences in therapy (especially trastuzumab) in patients treated in urban versus rural areas?

\section{Data Evaluation}

For selected characteristics, data were compared with findings from the Westdeutsches Brustcentrum (WBC) 2006, which includes data pertaining to the first diagnosis of breast cancer in 25,417 patients treated in 202 participating specialised institutions [7]. To evaluate adoption of recommended diagnostic and therapeutic schedules, we compared findings with the Arbeitsgemeinschaft Gynäkologische Onkologie (AGO) - Organkommission Mamma guidelines [8] and S3 Guidelines of the German Cancer Society (Deutsche Krebsgesellschaft, DKG) valid in 2007 [9], which were current at the time patients in this cohort were diagnosed and treated.

\section{Results}

\section{Patient and Disease Characteristics}

The present analysis included data from 5,397 patients diagnosed with breast cancer in 2007. The data captured in ONkeyLINE were at least $97 \%$ complete for relevant prognostic and decision-making factors (100\% for tumour location, $99.2 \%$ for tumour size, $97.5 \%$ for nodal status, $99.6 \%$ for axillary dissection/sentinel lymph node biopsy, 97.7\% for distant metastasis, and $100 \%$ for surgical procedure). Therefore, we assume that the data are of high quality and may be considered representative of breast cancer care in this population. Table 1 shows the demographic and tumour characteristics of the study population at diagnosis. Ten patients registered with breast cancer had sarcoma histopathology and thus are excluded from the rest of the analyses.

Decisions on treatment strategy depend heavily on accurate and thorough evaluation of tumour biology. Determination of hormone receptor status is crucial in treatment decisions. Almost all patients with invasive breast cancer should receive endocrine therapy. In non-invasive lesions, the decision whether or not to administer endocrine treatment has to be made on a case-by-case basis. It is recommended for patients aged $<50$ years as well as those with grade 3 (poorly differentiated) tumours or insufficient excision margins. In patients with ductal carcinoma in situ (DCIS), standard therapy comprises surgery and irradiation [9], and few patients will benefit from endocrine therapy. HER2 status determination is another key element in the treatment decision-making process. According to the S3 guideline [9], trastuzumab is indicated in patients with tumours that are HER2-positive, defined as immunohistochemistry (IHC) score $3+$ or IHC2+ with positive gene amplification demonstrated by fluores- cence in situ hybridisation (FISH) or chromogenic in situ hybridisation (CISH).

Table 2 summarises hormone receptor status in patients with invasive versus non-invasive breast cancer. Receptor status was determined in $>99 \%$ of patients with invasive breast cancer and $82 \%$ of those with non-invasive disease. Hormone receptor status was positive in $84 \%$ and $66 \%$ of patients, respectively. Table 3 summarises HER2 evaluation and status among patients with invasive breast cancer in our dataset. HER2 status was positive in 785 patients (17.3\%). Only 52 patients $(1.1 \%)$ had no evaluation of HER2 status. In a further 80 patients, HER2 status was IHC 2+, but neither FISH nor CISH was performed.

\section{Surgery}

The standard approach for invasive breast cancer is breastconserving surgery. However, not all patients are eligible (e.g. those with inflammatory carcinoma, positive microscopic margins after repeated excisions, or multicentric disease, and those ineligible for post-operative irradiation). In these cases, and in patients who choose not to have breast-conserving surgery, mastectomy is the recommended approach $[8,9]$. In the overall population (all tumour stages), breast-conserving surgery was performed in 3,717 patients (69\%). A further 1,569 patients $(29 \%)$ underwent mastectomy, while $101(2 \%)$ received no surgery. In the subgroup of 2,671 patients with stage pT1 (tumour size $<2 \mathrm{~cm}$ ), 2,242 patients $(84 \%)$ underwent breast-conserving surgery, 414 patients $(15 \%)$ had a mastectomy, and $15(0.6 \%)$ received no surgery.

Table 2. Evaluation of hormone receptor status

\begin{tabular}{lcc}
\hline $\begin{array}{l}\text { Hormone receptor } \\
\text { status }\end{array}$ & $\begin{array}{l}\text { Invasive breast cancer } \\
(\mathrm{n}=4,902), \mathrm{n}(\%)\end{array}$ & $\begin{array}{l}\text { Non-invasive breast } \\
\text { cancer }(\mathrm{n}=485), \mathrm{n}(\%)\end{array}$ \\
\hline Positive $^{\mathrm{a}}$ & $4,128(84.2)$ & $318(65.6)$ \\
Negative $^{\mathrm{b}}$ & $746(15.2)$ & $82(16.9)$ \\
Not determined & $19(0.4)$ & $81(16.7)$ \\
No information & $9(0.2)$ & $4(0.8)$ \\
\hline a $\geq 10 \%$ positive cells. & & \\
b $0 \%$ positive cells. & & \\
\hline
\end{tabular}

Table 3. Evaluation of HER2 status in patients with invasive breast cancer

\begin{tabular}{|c|c|}
\hline HER2 status & Patients, n (\%) \\
\hline Negative $^{a}$ & $3,697(81.5)$ \\
\hline Positive $^{\mathrm{b}}$ & 785 (17.3) \\
\hline Not determined & $52(1.1)$ \\
\hline No information & 11 \\
\hline $\begin{array}{l}\text { Intermediate positive (IHC } 2+\text { ), } \\
\text { no information for FISH/CISH }\end{array}$ & 26 \\
\hline $\begin{array}{l}\text { Intermediate positive (IHC } 2+\text { ), } \\
\text { no FISH/CISH performed }\end{array}$ & 80 \\
\hline \multicolumn{2}{|c|}{$\begin{array}{l}\text { aHC } 0 \text { or } 1+\text {, or } 2+\text { and FISH negative. } \\
\text { b IHC } 3+\text {, or } 2+\text { and FISH positive. } \\
\text { IHC }=\text { Immunohistochemistry; FISH = fluorescence in situ } \\
\text { hybridisation; } \mathrm{CISH}=\text { chromogenic in situ hybridisation. }\end{array}$} \\
\hline
\end{tabular}




\section{Radiotherapy}

Breast or chest wall irradiation is indicated following breastconserving surgery for invasive carcinoma or after mastectomy in patients with T3/T4 or positive microscopic margins. In addition, post-mastectomy irradiation is indicated in patients with at least 3 positive axillary nodes, especially in younger patients. Among 3,324 patients with invasive breast carcinoma or DCIS who underwent breast-conserving surgery, $89.4 \%$ received post-operative radiation therapy. In the remaining $11 \%$, no radiotherapy was documented after surgery.

\section{Endocrine Therapy}

Endocrine therapy is indicated in almost all patients with hormone receptor-positive invasive breast cancer, defined as $\geq 10 \%$ receptor-positive cells; endocrine responsiveness is classified as 'doubtful' in tumours with 1-9\% receptor-positive cells. Cases with unknown receptor status should be treated as endocrine responsive [10]. Among 4,128 patients with hormone receptor-positive invasive breast cancer, 2,911 (71\%) received adjuvant endocrine therapy (table 4$)$. Endocrine therapy was planned in an additional 342 patients (8\%). In the remaining 875 patients $(21 \%)$, no adjuvant endocrine therapy was documented (predominantly no information rather than confirmation that no endocrine therapy was administered).

\section{Chemotherapy}

An indication for chemotherapy depends on the presence of various risk factors, together with evaluation of the

Table 4. Adjuvant endocrine therapy in patients with hormone receptor-positive invasive breast cancer $(n=4,128)$

\begin{tabular}{lc}
\hline Age, years & $\begin{array}{l}\text { Adjuvant endocrine therapy, } \\
\mathrm{n}(\%)\end{array}$ \\
\hline$<20(\mathrm{n}=1)$ & $1(100)$ \\
$20-29(\mathrm{n}=9)$ & $6(66.7)$ \\
$30-39(\mathrm{n}=113)$ & $84(74.3)$ \\
$40-49(\mathrm{n}=554)$ & $383(69.1)$ \\
$50-59(\mathrm{n}=942)$ & $683(72.5)$ \\
$60-69(\mathrm{n}=1,478)$ & $1,086(73.5)$ \\
$70-79(\mathrm{n}=718)$ & $479(66.7)$ \\
$80-89(\mathrm{n}=299)$ & $184(61.5)$ \\
$90-99(\mathrm{n}=14)$ & $5(35.7)$ \\
Total $(\mathrm{n}=4,128)$ & $2,911(70.5)$ \\
\hline
\end{tabular}

benefit:risk ratio. Chemotherapy is indicated in patients considered to be at high risk, defined as those with 1-3 positive axillary nodes and hormone receptor-negative and/or HER2positive disease [10]. Patients with $>3$ positive axillary nodes, irrespective of hormone receptor and HER2 status, are also classified as high risk. Chemotherapy is not indicated in patients with low risk of local recurrence or distant metastasis, defined as meeting all of the following criteria: tumour size $<2 \mathrm{~cm}$ (pT1); negative nodal status ( $\mathrm{pN} 0)$; grade 1 tumour; age $>35$ years at first diagnosis; hormone receptor-positive tumour; and HER2 negative. Patients fulfilling neither of the above sets of criteria are classified as intermediate risk, and chemotherapy should be considered in these patients.

The ONkeyLINE data for chemotherapy are assumed to have a high level of completeness because chemotherapy typically starts a few weeks after surgery and is given by specialised institutions that are highly compliant with ONkeyLINE documentation. In addition, recording of chemotherapy administration in ONkeyLINE is obligatory for physicians responsible for oncology.

Among 846 patients classified as high risk, 557 (66\%) received chemotherapy (table 5). When analysed according to age category, the proportion of patients receiving chemotherapy for high-risk disease was highest in younger patients and showed an overall trend towards less frequent administration in older patients. Of the 2,423 patients at intermediate risk, 1,115 (46\%) received chemotherapy while in the remaining 1,308 patients $(54 \%)$ there was no documentation of chemotherapy in ONkeyLINE (table 5). Administration of chemotherapy was, as expected, less frequent in patients with intermediate-risk disease than high-risk breast cancer. As in the high-risk group, there was a trend towards less frequent use of chemotherapy with increasing age.

Analysis of chemotherapy administration according to the objective of treatment (adjuvant vs. palliative) revealed a similar relationship with age in both groups. In the adjuvant setting, $48 \%$ of 3,534 patients $<70$ years old received chemotherapy versus $17 \%$ of 1,079 patients aged $\geq 70$ years. Likewise, in the metastatic setting, $67 \%$ of 141 patients $<70$ years received chemotherapy versus only $34 \%$ of 76 patients $\geq 70$ years of age.

Table 5. Administration of chemotherapy according to risk category and age

\begin{tabular}{lcccc}
\hline Age group, years & \multicolumn{2}{c}{ High risk $(\mathrm{n}=846), \mathrm{n}(\%)$} & \multicolumn{2}{c}{ Intermediate risk $(\mathrm{n}=2,423), \mathrm{n}(\%)$} \\
\cline { 2 - 5 } & \multicolumn{1}{c}{ chemotherapy } & no chemotherapy & chemotherapy & no chemotherapy \\
\hline$<20$ & 0 & 0 & 0 & $5(44.4)$ \\
$20-29$ & $5(83.3)$ & $1(16.7)$ & $5(55.6)$ & $37(38.5)$ \\
$30-39$ & $37(74.0)$ & $13(26.0)$ & $59(61.5)$ & $134(36.1)$ \\
$40-49$ & $121(80.1)$ & $30(19.9)$ & $237(63.9)$ & $198(36.7)$ \\
$50-59$ & $144(77.4)$ & $42(22.6)$ & $341(63.3)$ & $393(50.8)$ \\
$60-69$ & $161(70.9)$ & $66(29.1)$ & $380(49.2)$ & $340(79.8)$ \\
$70-79$ & $87(51.8)$ & $51(48.2)$ & $66(20.2)$ & $189(96.9)$ \\
$80-89$ & $2(3.5)$ & $55(96.5)$ & 0 & $13(100)$ \\
$90-99$ & 0 & $1(100)$ & $1,115(46.0 \%)$ & $1,308(54.0 \%)$ \\
Total & $557(65.8 \%)$ & & & \\
\hline
\end{tabular}


Table 6. Adjuvant therapy with trastuzumab by age

\begin{tabular}{lc}
\hline Age category, years & $\begin{array}{l}\text { Patients receiving trastuzumab } \\
\mathrm{n}(\%)\end{array}$ \\
\hline $20-29(\mathrm{n}=3)$ & $2(66.7)$ \\
$30-39(\mathrm{n}=30)$ & $27(90.0)$ \\
$40-49(\mathrm{n}=89)$ & $67(75.3)$ \\
$50-59(\mathrm{n}=116)$ & $90(77.6)$ \\
$60-69(\mathrm{n}=139)$ & $106(76.3)$ \\
$70-79(\mathrm{n}=53)$ & $40(75.5)$ \\
$80-89(\mathrm{n}=3)$ & $2(66.7)$ \\
$90-99(\mathrm{n}=0)$ & $0(0)$ \\
Total $(n=433)$ & $334(77.1)$ \\
\hline
\end{tabular}

${ }^{a}$ Percentage of those with HER2-positive breast cancer $>1 \mathrm{~cm}$ and chemotherapy.

\section{Trastuzumab}

Positive HER2 status is a well-established predictive marker for trastuzumab therapy. Trastuzumab is recommended in the metastatic setting and as adjuvant therapy for patients with invasive breast tumours $>1 \mathrm{~cm}$. A total of 481 patients with HER2-positive breast tumours $>1 \mathrm{~cm}$ received trastuzumab. Trastuzumab was given predominantly in the adjuvant setting (428 patients; $89 \%$ of those receiving trastuzumab). Ten patients $(2 \%)$ received neoadjuvant trastuzumab, and 43 patients $(9 \%)$ were treated with trastuzumab in the palliative setting. Eighty-one patients received adjuvant trastuzumab not in accordance with guidelines, including 58 patients with tumours $<1 \mathrm{~cm}$.

The 2006 national guidelines made a strong recommendation for adjuvant trastuzumab therapy in patients with HER2positive breast cancers $>1 \mathrm{~cm}$ following adjuvant or primary chemotherapy. Overall, 433 patients met these criteria, of whom $334(77 \%)$ received the recommended treatment (table 6). The proportion of patients eligible but not treated with trastuzumab did not differ significantly between those aged $\geq 60$ versus $<60$ years ( 76 vs. $78 \%$, respectively). While the majority of women receiving adjuvant trastuzumab were treated in cancer centres (247 of 334 patients), there was no difference in the proportion of women who were treated according to the national guidelines between cancer centres and non-certified institutions (78 vs. $76 \%$ )

Further analysis of the data from ONkeyLINE showed that among the 428 patients receiving adjuvant trastuzumab in 2007 , treatment was given most commonly in a gynaecology clinic or internal medicine or oncology practice. Internal medicine or oncology practices were treating an average of 7 patients with trastuzumab compared with 4 patients in gynaecology clinics. The next most common location for adjuvant trastuzumab administration was gynaecology practices.

To explore the relationship between adjuvant trastuzumab therapy and place of residence, the population of Lower Saxony was divided into either urban $(>150,000$ inhabitants/ $\left.\mathrm{km}^{2}\right)$ or rural $\left(<150,000\right.$ inhabitants $\left./ \mathrm{km}^{2}\right)$ populations [11] In Lower Saxony, there are 4,979,673 inhabitants in urban areas (62\% of the population) and 3,003,012 inhabitants in rural areas $(38 \%)$. In the urban areas, $198(56 \%)$ of the 352 patients with HER2-positive disease (IHC $3+$ or FISH/ CISH-positive) received adjuvant trastuzumab. In rural areas, $129(61 \%)$ of the 210 patients with HER2-positive disease received trastuzumab.

\section{Discussion}

The population registered in ONkeyLINE represents approximately $85 \%$ of all cases in Lower Saxony during this period, and it is therefore reasonable to assume the analysis population is representative of the entire population of patients with breast cancer in this region. The general characteristics of the population (age distribution, histological subtype) are consistent with findings from other national cancer databases (SEER [12] and Krebs in Deutschland [13]).

The incidence of breast cancer peaks in patients aged 50-69 years. This age class is the target group for mammography screening in Germany [14]. Following the implementation of screening mammography in Germany, the proportion of patients presenting with non-invasive versus invasive carcinoma has risen [15]. The proportions of patients with locally advanced, regionally advanced, and metastatic disease at diagnosis in our dataset were very similar to the corresponding percentages in the SEER database. However, the proportion of patients with a more favourable prognosis at diagnosis was higher in our dataset than in the SEER database. This may reflect the more recent data collection in our analysis and the implementation of screening mammography. Furthermore, in the SEER database, only invasive breast cancer is registered, leading to imbalance between the dataset populations.

Hormone receptor status is a predictive marker for endocrine therapy. According to the S3 guideline, hormone receptor status should be determined in all invasive breast cancers and DCIS, but not in lobular carcinoma in situ (LCIS). In our dataset, hormone receptor status was determined in $99 \%$ of patients with invasive breast cancer and $83 \%$ of those with non-invasive carcinoma, giving an overall hormone receptor determination rate of $98 \%$. In the WBC dataset, the median combined rate of hormone receptor status assessment in invasive and non-invasive carcinoma was 97\% [7]. Our data suggest high quality of diagnosis and assessment in routine care in Lower Saxony. Only 19 patients $(0.4 \%)$ with invasive breast cancer and 85 patients $(18 \%)$ with non-invasive lesions lacked information on hormone receptor status. This may have been because of insufficient material for detection of receptor status in small tumours.

The quality of HER2 status documentation was very high. HER2 status was evaluated in $99 \%$ of patients with invasive breast cancer. This is similar to benchmark data from the WBC (98\% HER2 status evaluation in patients with invasive disease) [7]. 


\section{Surgery}

The rate of breast-conserving surgery is remarkably high ( $84 \%$ for stage pT1, 69\% overall). For first certification of breast cancer centres, a $50 \%$ rate of breast-conserving surgery is required; the required rate increases to $70 \%$ in stage $\mathrm{T} 1$ for re-certification [16]. The quality of surgery in early-stage disease (pT1) in Lower Saxony is even more impressive when considering that some of the patients in our dataset had noninvasive carcinoma and not all patients were treated in breast cancer centres. To put these data into context, breast-conserving surgery was documented in $68 \%$ of the overall population (all stages) in the WBC population and in $83 \%$ of those with stage pT1 disease [7], showing very close alignment.

\section{Radiotherapy}

Radiotherapy was not documented in $11 \%$ of patients. This is possibly explained by a delay in documentation when another adjuvant therapy, such as chemotherapy, is given before radiotherapy, and consequently irradiation begins after the documentation period. In this situation, repeated evaluation of the same patient group would show a higher degree of completeness. In most cases, non-compliance can be excluded because every patient undergoing breast-conserving surgery is advised of the need for post-operative irradiation. The $89 \%$ rate of radiotherapy in ONkeyLINE compares very favourably with the $70 \%$ rate reported in WBC [7]. This may be due to more rigorous documentation in ONkeyLINE.

\section{Endocrine Therapy}

Among patients with hormone receptor-positive invasive breast cancer in our dataset, adjuvant endocrine therapy was documented in $71 \%$ and planned in a further $8 \%$. In the remaining $21 \%$, endocrine therapy was not documented. In the WBC dataset, $94 \%$ of patients with hormone receptor-positive invasive breast cancer received adjuvant endocrine therapy [7]. However, an important difference in documentation is likely to explain the apparent discrepancy and lower use of endocrine therapy in Lower Saxony. For the WBC benchmarking, documentation of tumour data is obligatory. In contrast, documentation of treatment administration and follow-up data in the ONkeyLINE database is voluntary for non-specialised gynaecology practices, where the majority of patients receiving endocrine therapy are treated. Consequently, administration of endocrine therapy is almost certainly higher than suggested by our results. We anticipate increasing completeness of data as the number of practices documenting their follow-up online via ONkeyLINE increases. Nevertheless, some patients will refuse therapy or have a contraindication for endocrine therapy, such as osteoporosis or severe vascular disease. These factors may explain the less frequent administration of endocrine therapy in elderly women compared with their younger counterparts, especially in patients aged $>80$ years.

\section{Chemotherapy}

Chemotherapy is indicated in all patients with high-risk disease. However, some patients may refuse chemotherapy. In others, chemotherapy may be contraindicated, for example because of comorbidity or poor performance status. Our analysis showed that $66 \%$ of patients with high-risk disease received adjuvant chemotherapy. The use of adjuvant chemotherapy for high-risk disease decreased with increasing age. For example, among patients aged $>60$ years, only $70 \%$ received chemotherapy. Cardiac risk factors and other comorbidities are more common in older than younger women, possibly contributing to the lower proportion of older patients receiving adjuvant chemotherapy. The WBC 2006 data indicated that $60 \%$ of patients with at least 3 positive axillary nodes or hormone receptor-negative disease at first diagnosis of breast cancer received adjuvant chemotherapy [7]. Comparison with our results is difficult because the population defined by these criteria includes intermediate- as well as high-risk patients. While cardiac disease may be one factor contributing to the less frequent administration of chemotherapy among patients at high risk of recurrence, undertreatment in older patients is well documented in the literature [17-22].

\section{Trastuzumab}

Since 2006, AGO guidelines have recommended adjuvant trastuzumab in patients with HER2-positive tumours $>1 \mathrm{~cm}$. Overall, $77 \%$ of patients with invasive breast cancer, in whom trastuzumab was indicated, received adjuvant trastuzumab therapy according to the guidelines. A further 81 patients received adjuvant trastuzumab not in accordance with guidelines, including 58 patients with tumours $<1 \mathrm{~cm}$. Recent data suggest that trastuzumab is appropriate in patients with small tumours [23], and the latest (2010) AGO guidelines recommend trastuzumab in these patients. Undertreatment with trastuzumab was more pronounced in elderly patients. In this subgroup, a higher proportion of patients have comorbidities such as cardiac disease, which would preclude chemotherapy and therefore trastuzumab therapy.

The proportion of patients with HER2-positive disease was higher in urban than rural areas. However, the proportion of patients receiving trastuzumab was almost identical in these two areas, implying no difference in treatment according to locality. Every patient with breast cancer in Lower Saxony has access to diagnostics and therapy in a certificated breast cancer centre. These centres are distributed evenly throughout the region and with increasing mobility of patients, it appears that access to trastuzumab is not reduced in rural locations. The reimbursement of trastuzumab as soon as it gained regulatory approval may have contributed to the rapid uptake of trastuzumab into routine clinical practice. 


\section{Conclusions}

Data recorded in ONkeyLINE provide a high level of detail and can be assumed to be representative of medical care patterns in patients with breast cancer. These data show that diagnosis of breast cancer, including determination of hormone receptor and HER2 status, is routinely performed to a high standard according to clinical recommendations. A high proportion of patients with small tumours undergo breastconserving surgery, in accordance with requirements demanded of certified breast cancer centres.

Endocrine therapy is less well documented in ONkeyLINE, probably because it is frequently given outside the setting of certified breast cancer centres or specialist oncology practices. Our data suggest that endocrine therapy could be improved but the likely incompleteness of the data is a limitation. In contrast, data on chemotherapy and trastuzumab administration are quite comprehensive in ONkeyLINE. We observed age-dependent differences in chemotherapy administration. In younger patients, treatment practice was very close to that recommended in guidelines. However, in older patients, there is a tendency towards undertreatment. Overall, the high level of uptake of trastuzumab and rapid adoption of treatment guidelines is very encouraging. Within 1 year of inclusion of trastuzumab in treatment guidelines in Germany, $77 \%$ of women with HER2-positive disease, who met the guideline criteria, received adjuvant trastuzumab therapy. These findings appear to be consistent with other European countries. An audit in the UK indicated that $62 \%$ of patients with HER2-positive early breast cancer received trastuzumab
[24]. The most common reasons for not giving trastuzumab were tumour diameter $<1 \mathrm{~cm}$, age, comorbidity, and patient refusal. Recent data from The Netherlands indicated that $94 \%$ of 1,114 patients receiving adjuvant chemotherapy for HER2-positive breast cancer also received trastuzumab [25].

Typically trastuzumab is administered by specialist oncologic gynaecologists or specialist oncology internists, with equal distribution between clinics and practices. Of note, there was no evidence that patients in rural areas received different treatment from those living in urban areas. In summary, ONkeyLINE provides strong evidence to suggest that breast cancer care in all settings in Lower Saxony is of a high standard and generally consistent with treatment guidelines. Although the adoption of the national guidelines on adjuvant trastuzumab therapy in clinical practice is encouraging, the proportion of women who are undertreated is still high when compared with data from The Netherlands. As a new intervention, ONkeyLINE will interact with users when patients who meet guideline criteria for a specific therapy do not receive it, in order to improve compliance with national recommendations.

\section{Disclosure Statement}

This evaluation was financed by KVN. Roche Germany provided an unrestricted grant for this work and had the opportunity to review the draft manuscript. However, both the decision to submit the paper for publication and the final approval of the manuscript remained the responsibility of the authors.

\section{References}

1 Epidemiologisches Krebsregister Niedersachsen (EKN): Krebs in Niedersachsen 2004. pp. 36-7

2 Blamey RW, Hornmark-Stenstam B, Ball G, Blichert-Toft M, Cataliotti L, Fourquet A, Gee J, Holli K, Jakesz R, Kerin M, Mansel R, Nicholson R, Pienkowski T, Pinder S, Sundquist M, van de Vijver M, Ellis I: ONCOPOOL - a European database for 16,944 cases of breast cancer. Eur J Cancer 2010;46:56-71.

3 Haberland J, Bertz J, Wolf U, Ziese T, Kurth BM: German cancer statistics 2004. BMC Cancer 2010;10:52.

4 Waldmann A, Pritzkuleit R, Raspe H, Katalinic A: Guideline-compatible treatment of breast cancer patients. Dtsch Arztebl Int 2008;105:337-343.

5 Hofmann S: ONkeyLINE ist mit seiner Benutzerfreundlichkeit und Datensicherheit die medizinische Tumordokumentation der Zukunft. Nds. Ärzteblatt 2004:6:59.

6 Krüger-Brand HE: Elektronische Tumourdokumentation: Bessere Nachsorge für Krebspatienten. Dtsch Ärzteblatt 2005;102:A640.

7 Westdeutsches Brustcentrum (WBC): Jahresauswertung Benchmarking Brustzentren WBC 2006.
8 AGO - Organkommission Mamma: Diagnosis and Treatment of patients with primary or metastatic breast cancer. Guidelines of the AGO Breast Commission. München, Zuckschwerdt Verlag GmbH, 2006.

9 Deutsche Krebsgesellschaft: Interdisziplinäre S3Leitlinie für die Diagnostik, Therapie und Nachsorge des Mammakarzinoms. München, Zuckschwerdt-Verlag, 2006.

10 Goldhirsch A, Wood WC, Gelber RD, Coates AS, Thürlimann B, Senn HJ; 10th St. Gallen conference: Progress and promise: highlights of the international expert consensus on the primary therapy of early breast cancer 2007. Ann Oncol 2007; 18:1133-1144.

11 OECD: OECD Regions at a Glance. Paris, OECD, 2007.

12 Horner MJ, Ries LAG, Krapcho M, Neyman N, Aminou R, Howlader N, Altekruse SF, Feuer EJ, Huang L, Mariotto A, Miller BA, Lewis DR, Eisner MP, Stinchcomb DG, Edwards BK (eds): SEER Cancer Statistics Review, 1975-2006. Bethesda, MD, National Cancer Institute.

13 Krebs in Deutschland 2003-2004: Häufigkeiten und Trends. 6. überarbeitete Auflage. Berlin, Robert Koch-Institut (Hrsg) und die Gesellschaft der epidemiologischen Krebsregister in Deutschland e. V. (Hrsg), 2008, pp. 54-7.
14 Albert US, Altland H, Duda V, Engel J, Geraedts M, Heywang-Köbrunner S, Holzel D, Kalbheim E, Koller M, König K, Kreienberg R, Kühn T, Lebeau A, Nass-Griegoleit I, Schlake W, Schmutzler R, Schreer I, Schulte H, SchulzWendtland R, Wagner U, Kopp I: 2008 update of the guideline: early detection of breast cancer in Germany. J Cancer Res Clin Oncol 2009;135:339_ 354.

15 Ernster VL, Barclay J: Increases in ductal carcinoma in-situ (DCIS) of the breast in relation to mammography: a dilemma. J Natl Cancer Inst Monogr 1997;22:151-156.

16 Deutsche Krebsgesellschaft. Deutsche Gesellschaft für Senologie: Fachliche Anforderungen für die Zertifizierung von Brustzentren durch die Deutsche Krebsgesellschaft und die Deutsche Gesellschaft für Senologie. Berlin, 2003.

17 Silliman RA: When cancer in older adults is undermanaged: the breast cancer story. J Am Geriatr Soc 2009;57(suppl 2):S259-S261.

18 Protière C, Viens P, Rousseau F, Moatti JP Prescribers' attitudes toward elderly breast cancer patients. Discrimination or empathy? Crit Rev Oncol Hematol 2010;75:138-150. 
19 Buist DS, Chubak J, Prout M, Yood MU, Bosco JL, Thwin SS, Gold HT, Owusu C, Field TS, Quinn VP, Wei F, Silliman RA: Referral, receipt, and completion of chemotherapy in patients with early-stage breast cancer older than 65 years and at high risk of breast cancer recurrence. J Clin Oncol 2009;27:4508-4514.

20 Crivellari D, Aapro M, Leonard R, von Minckwitz G, Brain E, Goldhirsch A, Veronesi A, Muss $\mathrm{H}$ : Breast cancer in the elderly. J Clin Oncol 2007;25:1882-1890.

21 Silliman RA, Troyan SL, Guadagnoli E, Kaplan SH, Greenfield S: The impact of age, mental status and physician-patient interactions on the care of older women with breast carcinoma. Cancer 1997;80:1326-1334.
22 Newschaffer CJ, Penberthy L, Desch CE, Retchin SM, Whittemore M: The effect of age and comorbidity in the treatment of elderly women with non-metastatic breast cancer. Arch Intern Med 1996;156:85-90.

23 Gonzalez-Angulo AM, Litton JK, Broglio KR, Meric-Bernstam F, Rakkhit R, Cardoso F, Peintinger F, Hanrahan EO, Sahin A, Guray M, Larsimont D, Feoli F, Stranzl H, Buchholz TA, Valero V, Theriault R, Piccart-Gebhart M, Ravdin PM, Berry DA, Hortobagyi GN: High risk of recurrence for patients with breast cancer who have human epidermal growth factor receptor 2-positive, node-negative tumors $1 \mathrm{~cm}$ or smaller. J Clin Oncol 2009;27:5700-5706.
24 Marla S, Cardale J, Dodwell DJ, Skene AI, Abram P, Palmieri C, Cleator SJ, Gojis O, Tovey SM, Doughty JC: A multicenter audit of HER2 positive early breast cancers and the reasons why patients do not receive trastuzumab therapy. Eur J Cancer Suppl 2010;8:85(abstr 94).

25 De Munck L, Schaapveld M, Siesling S, Otter R, Willemse PHB: Implementation of adjuvant trastuzumab in breast cancer patients in The Netherlands. Eur J Cancer Suppl 2010;8:69(abstr 36). 